\title{
Changing the Hydrate Management Guidelines: From Benchtop Experiments to CSMHyK Field Simulations (Support Information)
}

Yan Wang $^{a}$, Siva Subramanian ${ }^{b}$, Douglas Estanga ${ }^{b}$, Ahmad A. A. Majid $^{a, d}$, Sijia Hu ${ }^{a}$, Davi C. Salmin $^{a}$, Carolyn A. Koh ${ }^{a}$, Luis E. Zerpa ${ }^{a, c^{*}}$

a Center for Hydrate Research, Department of Chemical \& Biological Engineering, Colorado School of Mines, 1600 Illinois St., Golden, CO 80401, USA

${ }^{b}$ Flow Assurance Solutions Team, Chevron ETC, 1400 Smith St, Houston, TX, 77002, USA

$c^{*}$ Department of Petroleum Engineering, Colorado School of Mines, 1600 Arapahoe St., Golden, CO 80401, USA.

${ }^{d}$ Faculty of Chemical \& Natural Resources Engineering, University Malaysia Pahang, Malaysia.

Table S1 Gas Analysis

\begin{tabular}{|l|l|}
\hline Compositions & Mole \% \\
\hline $\mathrm{N}_{2}$ & 0.73 \\
$\mathrm{CO}_{2}$ & 1.02 \\
Methane & 43.43 \\
Ethane & 13.08 \\
Propane & 16.00 \\
i-Butane & 2.55 \\
n-Butane & 9.62 \\
i-Pentane & 4.32 \\
n-Pentane & 6.80 \\
C6+ & 2.45 \\
\hline
\end{tabular}




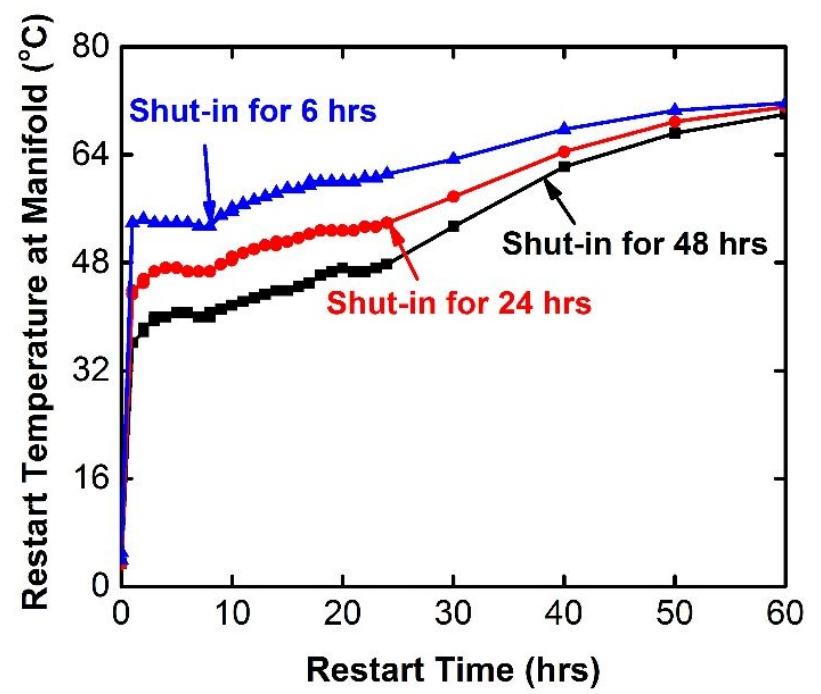

Figure S1: Field production restart manifold temperature at 25 vol. $\%$ water cut as a function of restart time after 6, 24, and 48 hrs of shut-in.

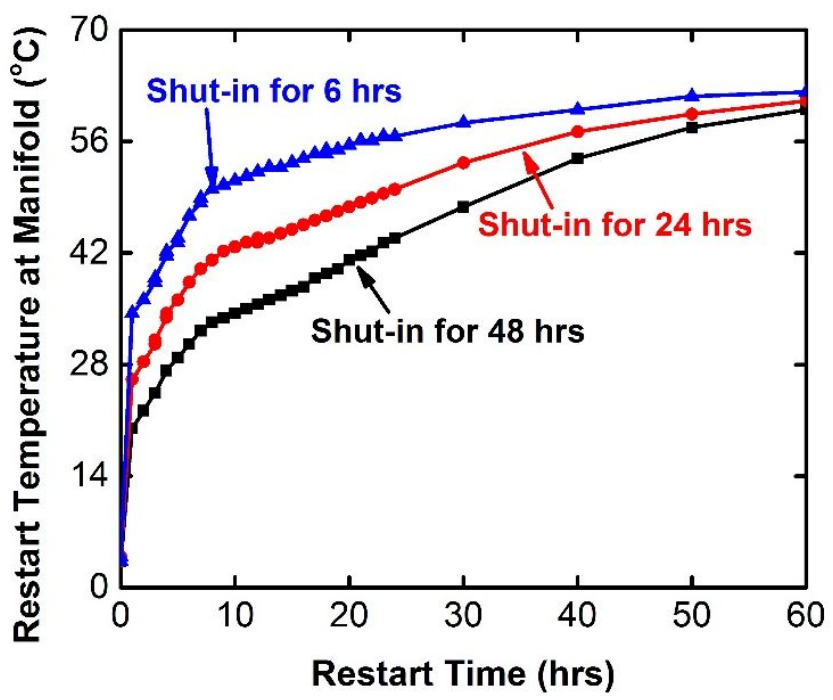

Figure S2: Field production restart manifold temperature at 57 vol. $\frac{\circ}{\circ}$ water cut as a function of restart time after 6, 24, and 48 hrs of shut-in. 


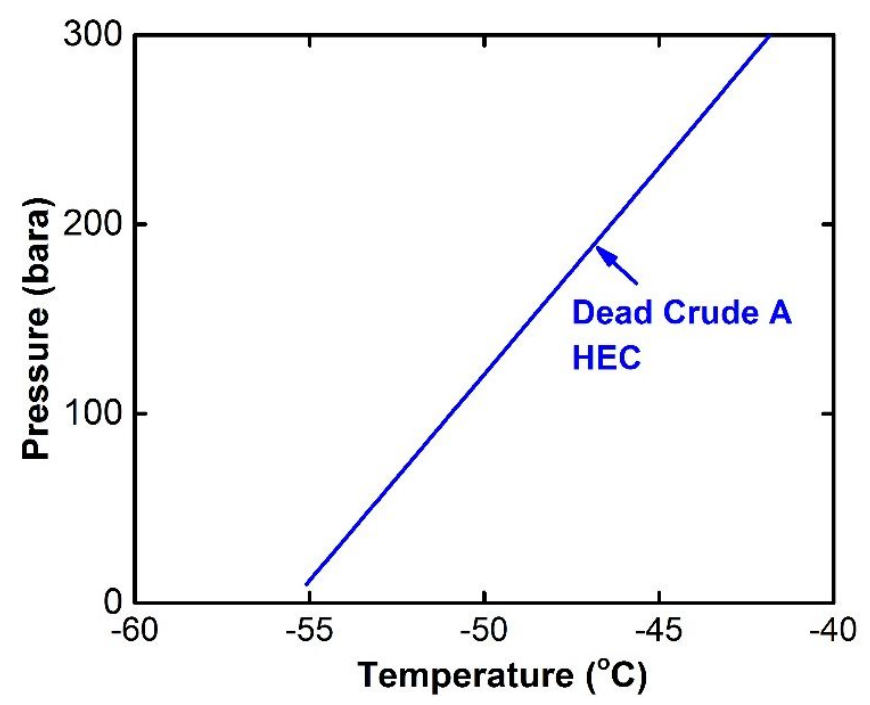

Figure S3: Dead crude A hydrate equilibrium curve (HEC) at various pressures and temperatures.

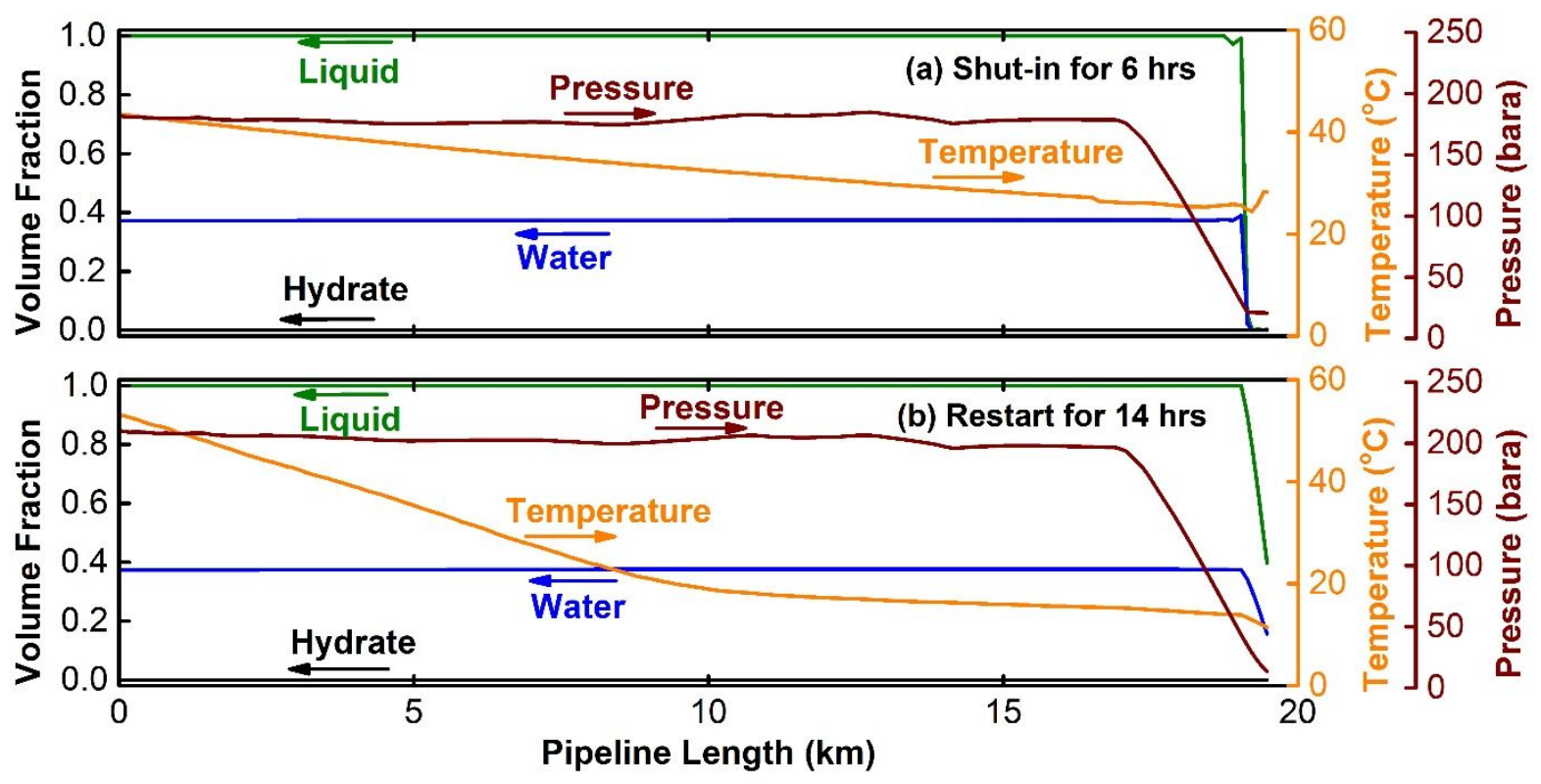

Figure S4: Fluid, temperature and pressure distribution along the pipeline length at 40 vol.\% water cut after (a) shutting in for $6 \mathrm{hrs;}$ (b) restart for $14 \mathrm{hrs}$. 

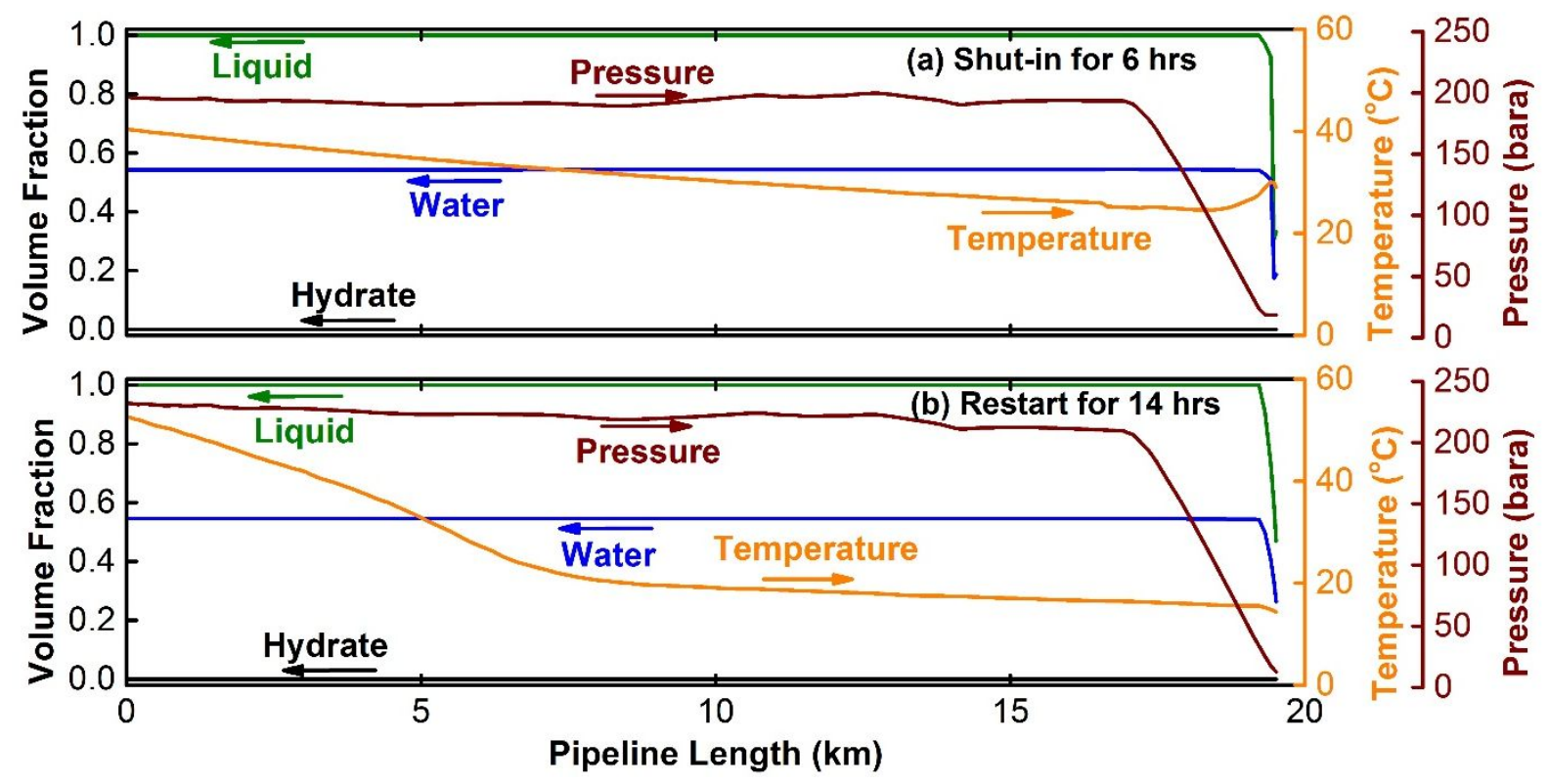

Figure S5: Fluid, temperature and pressure distribution along the pipeline length at 57 vol.\% water cut after (a) shutting in for $6 \mathrm{hrs}$; (b) restart for $14 \mathrm{hrs}$.

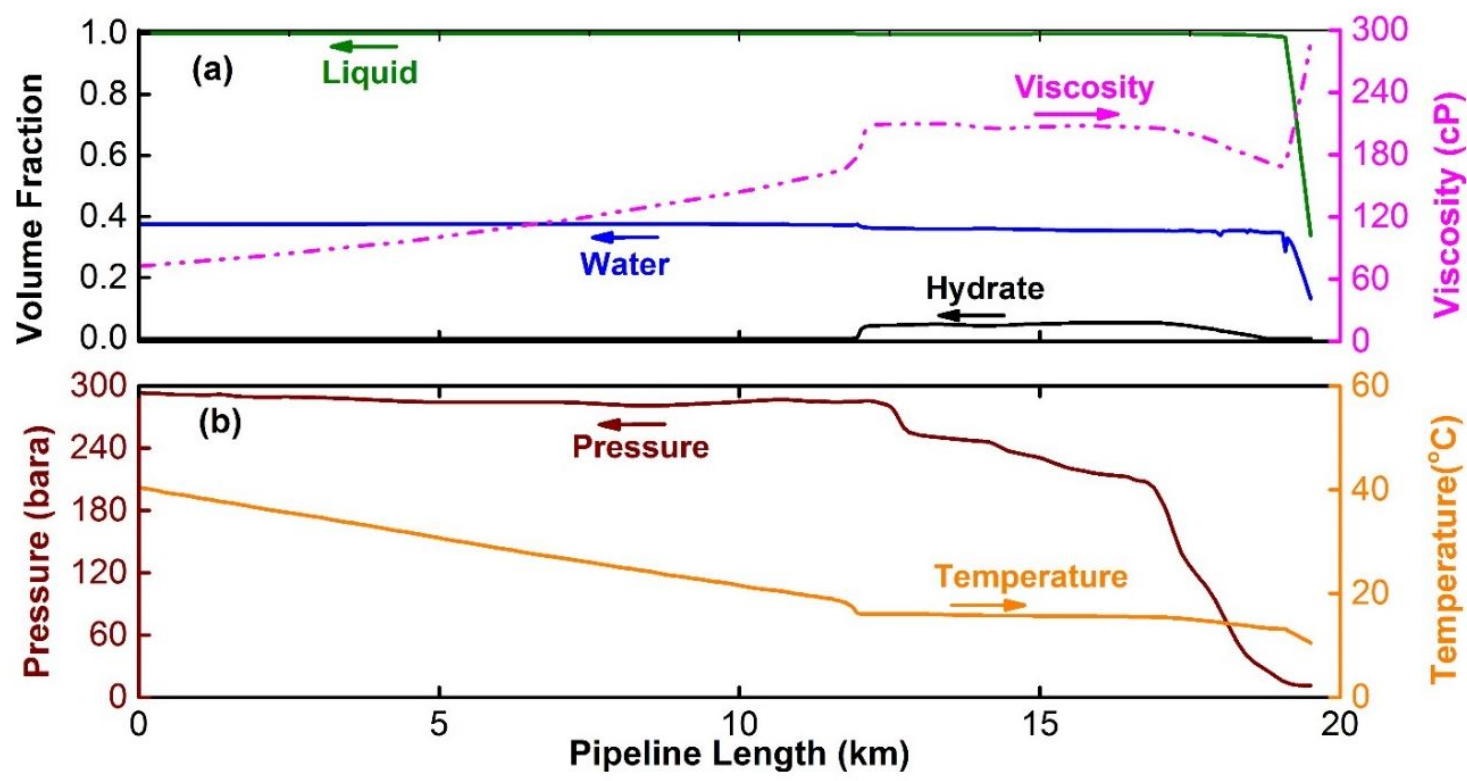

Figure S6: Simulation results at 40 vol. $\%$ water cut after shutin for 10 hrs and then restart the production for $18 \mathrm{hrs}\left(C_{\text {oil }}=\right.$ 0.1). (a) Fluid and viscosity distribution along the pipeline length; (b) Temperature and pressure distribution along the pipeline length. 


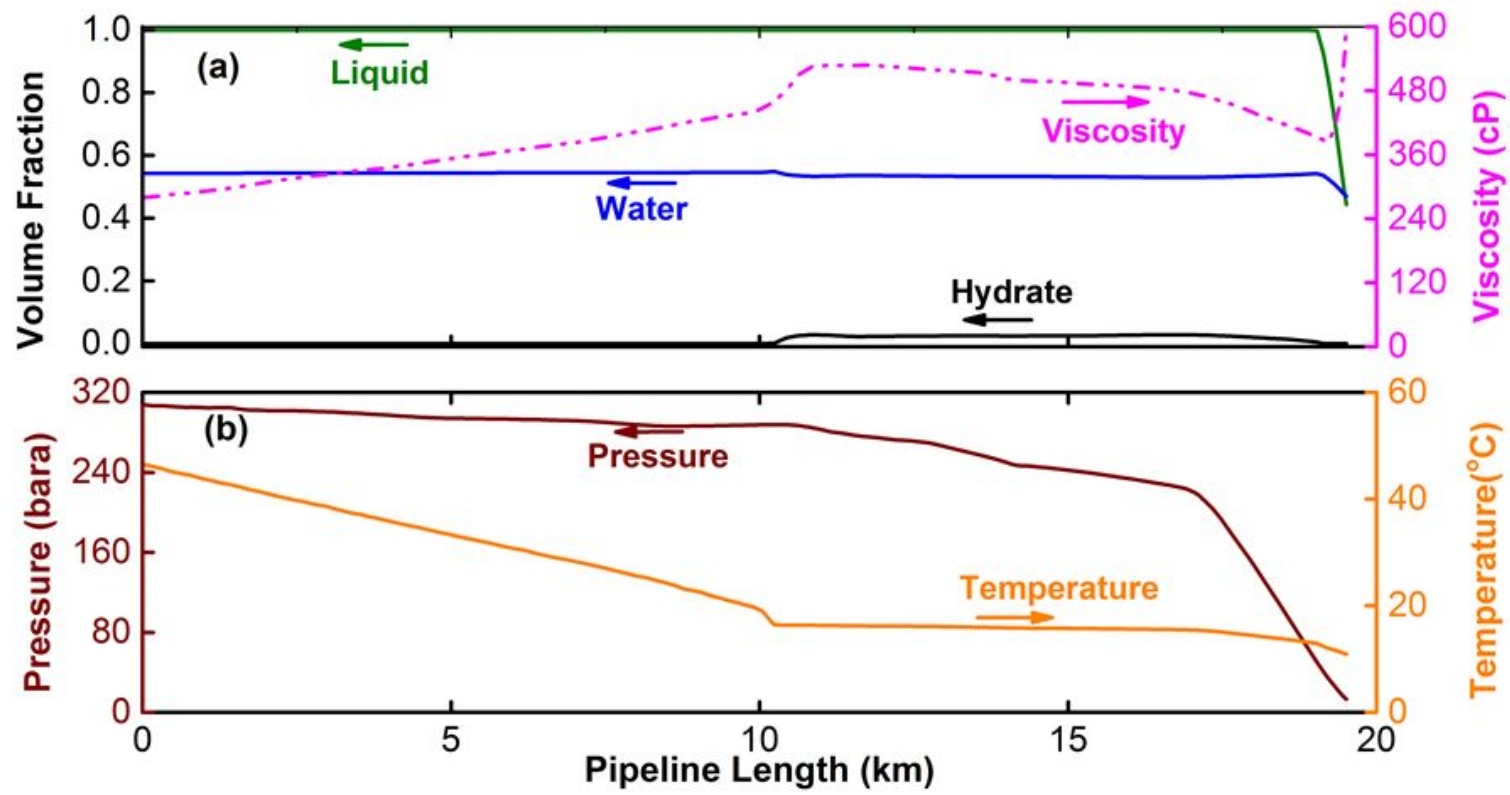

Figure S7: Simulation results at 57 vol.\% water cut after shutin for 10 hrs and then restart the production for 18 hrs $\left(C_{\text {oil }}=\right.$ 0.1). (a) Fluid and viscosity distribution along the pipeline length; (b) Temperature and pressure distribution along the pipeline length.

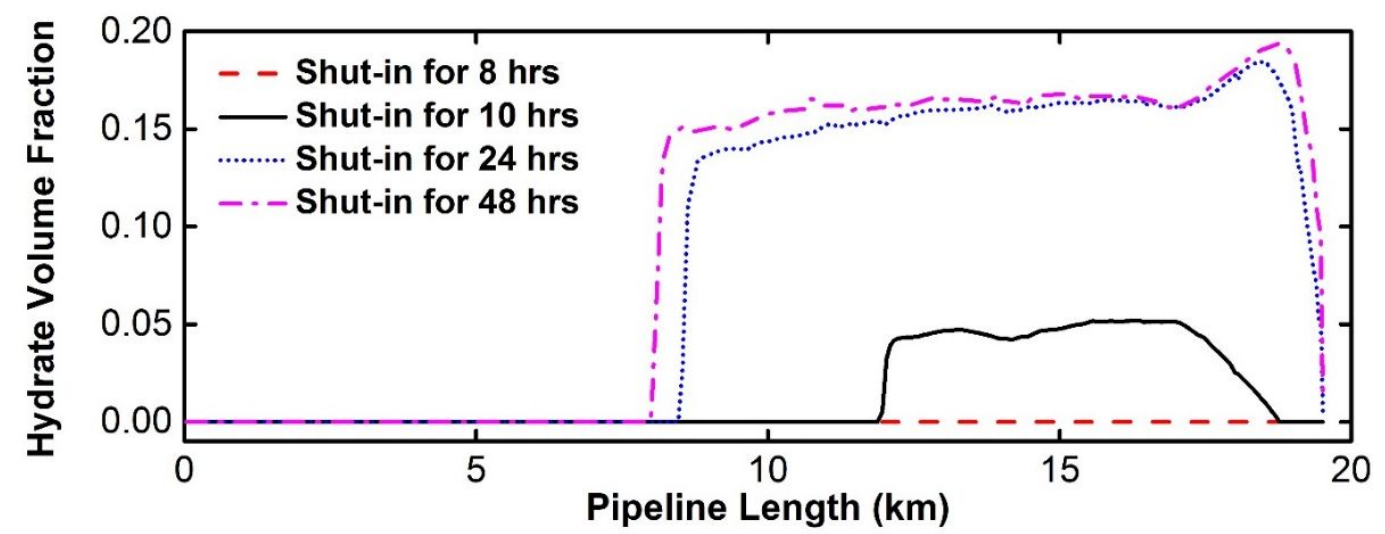

Figure S8: Hydrate volume fraction along the pipeline length at 40 vol. $\frac{\circ}{\circ}$ water cut after shut-in for different times (8, 10, 24, and 48 hrs $)$ and then restart the production for $18 \mathrm{hrs}\left(C_{\text {oil }}=\right.$ $0.1)$. 


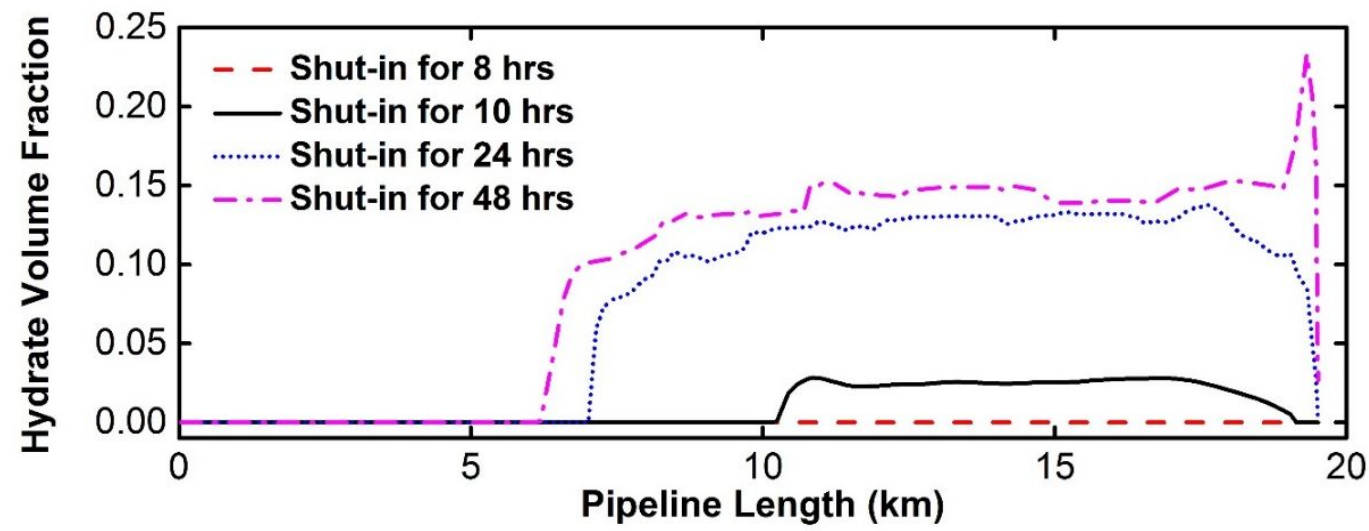

Figure S9: Hydrate volume fraction along the pipeline length at 57 vol. $\frac{\circ}{\circ}$ water cut after shut-in for different times $(8,10,24$, and $48 \mathrm{hrs})$ and then restart the production for $18 \mathrm{hrs}\left(C_{\text {oil }}=\right.$ $0.1)$.

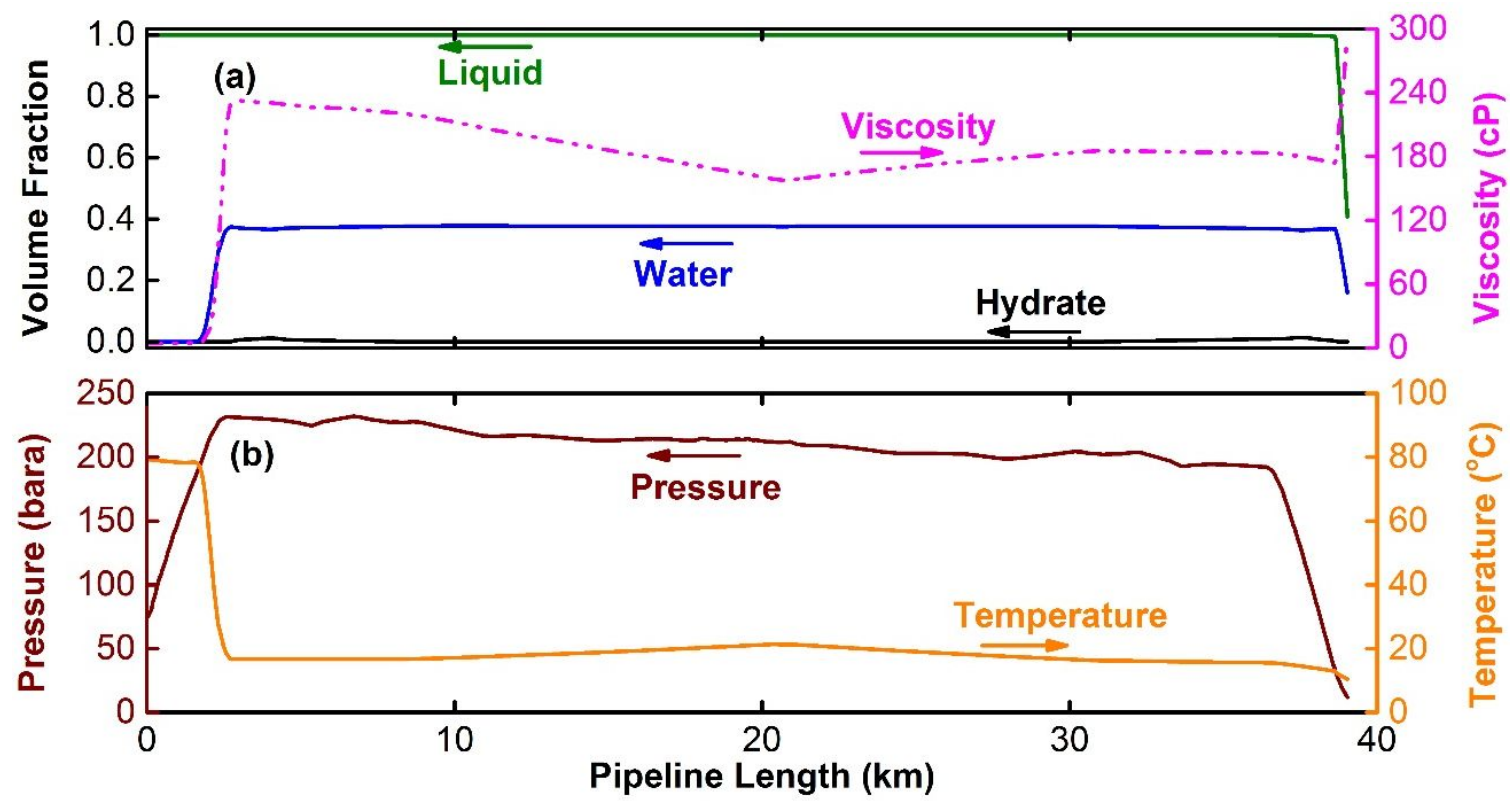

Figure S10: Simulation results at 40 vol. $\%$ water cut after shut-

in for 16 hrs and then displacing the fluids in the pipeline with dead oil for 1 hr $\left(C_{o i l}=1\right)$. The left of the pipeline is the topside dead oil injection position and the total length is that of the flowline loop. (a) Fluid and viscosity distribution along the pipeline length; (b) Temperature and pressure distribution along the pipeline length. 


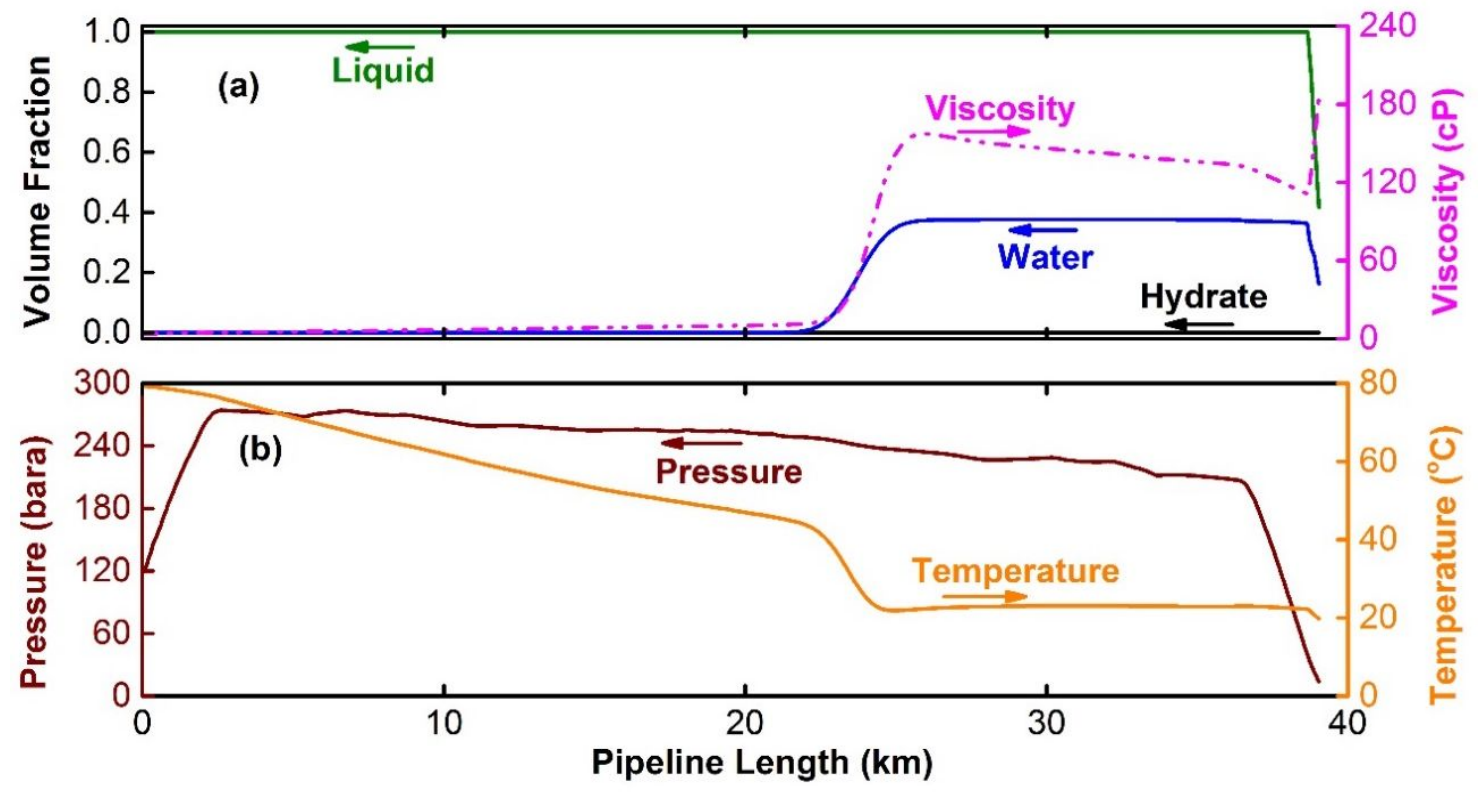

Figure S11: Simulation results at 40 vol.\% water cut after shutin for 16 hrs and then displacing the fluids in the pipeline with dead oil for 4 hrs $\left(C_{o i l}=1\right)$. The left of the pipeline is the topside dead oil injection position and the total length is that of the flowline loop. (a) Fluid and viscosity distribution along the pipeline length; (b) Temperature and pressure distribution along the pipeline length.

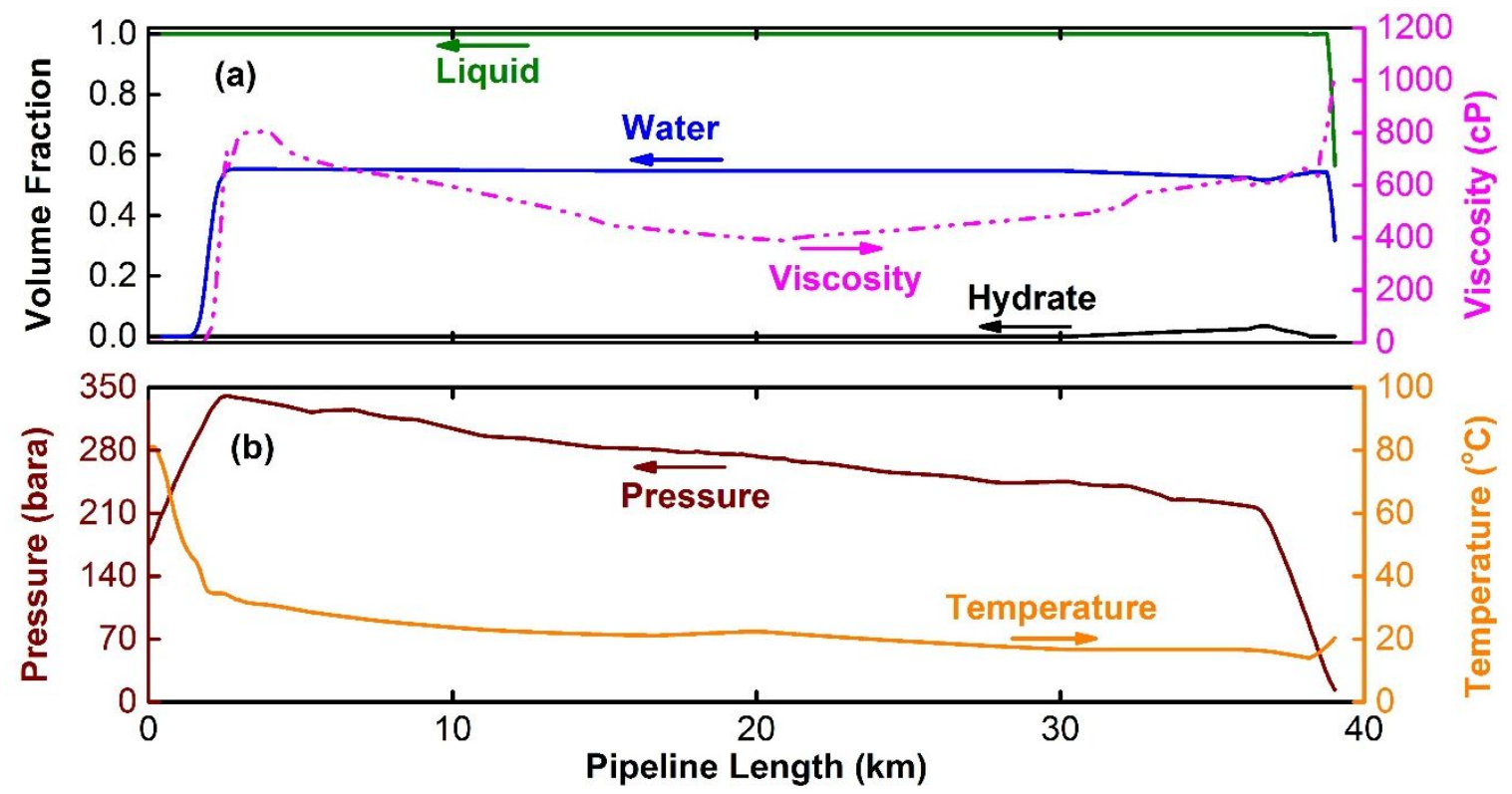


Figure S12: Simulation results at 57 vol.\% water cut after shutin for 16 hrs and then displacing the fluids in the pipeline with dead oil for 1 hr $\left(C_{o i l}=1\right)$. The left of the pipeline is the topside dead oil injection position and the total length is that of the flowline loop. (a) Fluid and viscosity distribution along the pipeline length; (b) Temperature and pressure distribution along the pipeline length.

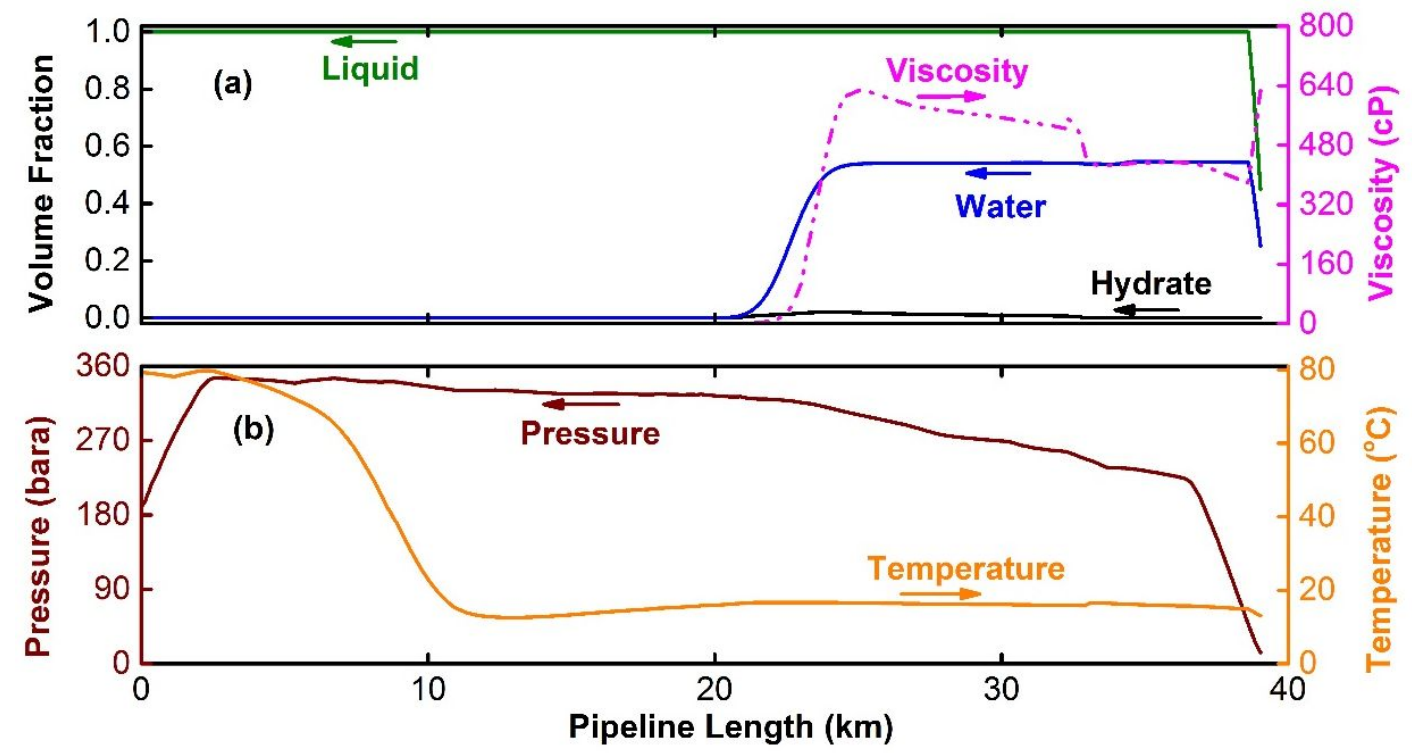

Figure S13: Simulation results at 57 vol.\% water cut after shutin for 16 hrs and then displacing the fluids in the pipeline with dead oil for 4 hrs $\left(C_{o i l}=1\right)$. The left of the pipeline is the topside dead oil injection position and the total length is that of the flowline loop. (a) Fluid and viscosity distribution along the pipeline length; (b) Temperature and pressure distribution along the pipeline length. 